\title{
Outcomes of the Ontario Bariatric Network: a cohort study
}

\author{
Fady Saleh MD MPH, Aristithes G. Doumouras MD, Scott Gmora MD, Mehran Anvari MD PhD, \\ Dennis Hong MD MSc
}

\section{Abstract}

Background: Bariatric surgery centres of excellence are relatively new in Canada and were first started in Ontario in 2009. This study presents short-term outcomes of Canada's largest bariatric collaborative, from Ontario, during its first 3 years.

Methods: We performed a population-based cohort study that included all patients (age $\geq 18$ ) who received a Roux-en-Y gastric bypass or sleeve gastrectomy for the purpose of weight loss from March 2009 to April 2012 within Ontario. Data were derived from the Canadian Institute for Health Information Discharge Abstract and Hospital Morbidity Databases. Primary outcomes included short-term overall complication rate, reoperation rate, anastomotic leak rate and death. Hierarchical logistic regression was used to identify risk factors for overall complications. A median odds ratio (OR) was used to compare risk-adjusted complication rates across centres of excellence.

Results: A total of 5007 procedures (91.7\% Roux-en-Y gastric bypass, 8.3\% sleeve gastrectomy) were performed during the 3-year study period, with an overall complication rate of $11.7 \%$ (95\% confidence interval [Cl] $10.8 \%-12.6 \%)$. The leak rate was $0.84 \%(95 \%$ $\mathrm{Cl} 0.61 \%-1.13 \%)$, the reoperation rate was $4.6 \%(95 \% \mathrm{Cl} 4.0 \%-5.2 \%)$ and mortality was $0.16 \%(95 \% \mathrm{Cl} 0.07 \%-0.31 \%)$. Male sex, chronic kidney disease and osteoarthritis were identified as risk factors for overall complications $(p$ value $<0.05)$. The median ORs across centres of excellence, calculated for both overall complications and reoperation rate, were 1.76 and 1.49 , respectively.

Interpretation: Bariatric surgery within Ontario has similar short-term outcomes to those of other major world centres. The variability of outcomes within centres of excellence highlights areas for program quality improvement.

besity remains a growing national and global epidemic. Obesity rates across Canada are estimated to be greater than $20 \%$ among adults, ${ }^{1}$ with a much higher prevalence of overweight individuals, at $65 \%$ and $49 \%$ for adult men and women, respectively. Since 1985 , rates of obesity have increased $300 \%$ while rates of morbid obesity, a body mass index (BMI) greater than 40, have increased fivefold. ${ }^{2}$ Obesity poses substantial health risks, including cardiac disease, hypertension, diabetes mellitus and, ultimately, premature death. ${ }^{3,4}$ In 2006, obesity-related illnesses resulted in an estimated $\$ 3.9$ billion in direct costs in Canada, with an additional $\$ 3.2$ billion for indirect costs; these amounts have likely increased over time. ${ }^{5}$

Bariatric surgery has been proposed as a treatment for obesity and its associated comorbidities. The surgery has been shown to result in sustainable weight reduction, with longterm data showing patients maintaining $50 \%$ or greater loss of excess weight after gastric bypass surgery. ${ }^{6-8}$ In addition, bariatric surgery, depending on the type of procedure, has a substantial impact on remission and improvement in obesityrelated illnesses. In studies with 2 or more years of follow-up after gastric bypass surgery, $67 \%$ of patients diagnosed with diabetes, 38\% with hypertension and $60 \%$ with hyperlipidemia remained disease-free after surgery; ${ }^{7}$ reduced illness severity was attained in additional patients who did not achieve remission. ${ }^{9}$ Studies have also shown a $50 \%$ reduction in mortality after bariatric surgery and an improvement in the quality of life of patients that accompanies their weight loss and improvement in overall health. ${ }^{10,11}$

The objective of this study was to publish short-term outcomes after bariatric surgery in Canada's largest regional bariatric surgery program, and to compare short-term outcomes between sites. We hypothesize that outcomes of the Ontario Bariatric Network would be similar to other major international centres, with little variation across centres within the program.

\section{Competing interests: None declared.}

This article has been peer reviewed.

Correspondence to: Dennis Hong, dennishong70@gmail.com

CMAJ Open 2016. DOI:10.9778/cmajo.20150112 


\section{Methods}

\section{Design and setting}

This was a retrospective cohort study in which the principle objective was to evaluate short-term outcomes after bariatric surgery in Ontario between fiscal years 2009 and 2011.

In Ontario, publicly funded out-of-country bariatric surgery was common and increasing before the establishment of Canadian bariatric programs, peaking in 2009 at just under 2000 procedures, most of which were performed in the United States. ${ }^{12,13}$ Bariatric surgery across the province was sparsely performed until the Ministry of Health devoted \$75 million to establishing Ontario's 4 centres of excellence, managed by the Ontario Bariatric Network, to carry out Roux-en$\mathrm{Y}$ gastric bypass and longitudinal sleeve gastrectomy surgeries. ${ }^{14}$

Publicly funded bariatric surgery in Ontario was performed within the following sites during the study period: University of Toronto Bariatric Collaborative, Toronto, Ont., St. Joseph's Hospital, Hamilton, Ont., the Ottawa Hospital Civic Campus, Ottawa, Ont., and Guelph General Hospital, Guelph, Ont. Although the latter 3 sites include only a single hospital, the University of Toronto Collaborative program consists of 5 different hospitals jointly administered by the collaborative. The minimum criteria for a hospital to receive centre of excellence status include being a full acute care/ inpatient facility with a 24-hour intensive care unit, emergency and surgical coverage; at least 2 fellowship-trained bariatric surgeons with a minimum of 50 cases per year and a total volume of 120 cases per year; and multidisciplinary medical, psychiatric and respiratory support for preoperative, postoperative and clinic care. ${ }^{13,15}$

\section{Sources of data}

Patient demographics, comorbidity profiles, surgical procedures and complications were derived from the Canadian Institute for Health Information Discharge Abstract Database and Hospital Morbidity Database. These are comprehensive databases that document inpatient admissions, including comorbidities and in-hospital complications. The institute is highly accurate in documenting most responsible diagnoses and primary surgical procedures, which are validated and widely used to identify patients for study inclusion. ${ }^{16,17}$ However, the accuracy in capturing comorbidities is low. ${ }^{18}$ In addition, BMI data were unavailable for use in this study. This study was approved by the research ethics board of St. Joseph's Hospital, Hamilton, Ontario.

\section{Population}

All patients, 18 years of age or older, who underwent bariatric surgery at a centre of excellence within Ontario during fiscal years 2009 to 2011 for the purpose of weight loss were included in the study. Patients were identified using obesity as the most responsible diagnosis (International Statistical Classification of Diseases and Related Health Problems, 10th revision [ICD-10] codes E65, E66.0, E66.8, E66.9), with 1 of the funded bariatric procedures: a sleeve gastrectomy
(Canadian Classification of Health Interventions codes 1NF78GB, 1NF78WJ) or Roux-en-Y gastric bypass (Classification of Health Interventions codes 1NF78SH, 1NF78DQ). Indications for surgery were based on National Institutes of Health criteria. ${ }^{19}$

\section{Outcomes}

Outcomes within this study had to have occurred during the index admission or during a readmission within 30 days of the index bariatric procedure. The outcomes of interest in this study included overall complications, reoperation, anastomotic leak and death. Overall complications included any complication that occurred during the exposure period. This was a composite outcome and was determined using ICD-10 codes for diagnoses that developed during the hospital admission. Reoperations were unplanned events that occurred any time after the initial elective operation for weight loss. Anastomotic leak was defined as having occurred if a reoperation was required, if the operative procedure included a washout (Classification of Health Interventions codes 1OT52DA, 1OT52DATS, 1OT52LA, 1OT52LATS) and if postoperative hemorrhage was not a complication so as to avoid confusion with the need for a washout.

\section{Statistical analysis}

Descriptive statistics were used to characterize the patient population. The $\chi^{2}$ statistic was used to compare categorical variables and analyses of variance (ANOVA) were used for continuous variables. Hierarchical logistic regression was used to determine predictors of complications, using the log (odds) of the binary outcome modelled as a linear function of important baseline characteristics, which were selected a priori. These baseline covariates were entered into the model as fixed effects, whereas centre of excellence was entered as a random effect to adjust for clustering within centres. Age was the only continuous variable and was entered as such into the model. No data were missing for the variables used in the statistical models. Odds ratios (ORs) with $95 \%$ confidence intervals (CIs) comparing clustering between hospitals were estimated, comparing each hospital to the mean overall complication rate. This was done for reoperation rate in a similar way. A median OR was also estimated to assess overall complication and reoperation rate variability between centres of excellence using the hierarchical models. ${ }^{20}$ The median OR is a measure of variability between centres of excellence and can be interpreted as the median value of the OR of complication when taking the same patient from a centre of higher risk to a centre of lower risk. A sensitivity analysis was performed on the effect of low prevalence comorbidities on the point estimates of other variables within the multivariable model and on the median ORs. Specifically, the low prevalence comorbidities of osteoarthritis, coronary artery disease, chronic obstructive pulmonary disease and chronic kidney disease were removed individually and as a group. Statistical significance was set at $p<0.05$. Data were analyzed using Stata (StataCorp version 12.1; College Station, TX). 


\section{Results}

Table 1 presents characteristics of the study population. From 2009 to 2011, 5007 patients underwent bariatric surgery in Ontario for the purpose of weight loss. Roux-en-Y gastric bypass accounted for about $92 \%$ of procedures, whereas sleeve gastrectomy comprised the remainder. Almost all procedures (99\%) were done laparoscopically (data not shown). The mean age of the cohort was 44.6 years (standard deviation [SD] \pm 10.3 ) and $81.9 \%$ of patients were female. Obstructive sleep apnea, diabetes, hypertension and gastresophageal reflux affected 30.9\%, 29.6\%, 27.2\% and $6.6 \%$ of patients, respectively. Reflecting the higher risk profile of gastric bypass as compared with sleeve gastrectomy, bypass patients tended to be younger $(44.4 \mathrm{v} .47 .0 \mathrm{yr}$; $p<0.001)$, were less likely to be male $(17.8 \%$ v. $21.6 \% ; p=$ 0.05 ) and had fewer comorbidities, with lower rates of obstructive sleep apnea, chronic kidney disease, hypertension, coronary artery disease and chronic obstructive pulmonary disease $(p<0.05)$.

The complications are displayed in Table 2. Overall complication rate was $11.7 \%$ (95\% confidence interval [CI] $10.8 \%-1 \% 2.6$ ), with $11.9 \%$ occurring in the bypass group and $9.9 \%$ in the sleeve gastrectomy group $(p=0.2)$. There were a total of 8 deaths during the study, yielding mortality of $0.16 \%$ (95\% CI $0.07 \%-0.31 \%)$, which was not statistically different in either group $(0.15 \%$ in the bypass group v. $0.24 \%$ in the sleeve gastrectomy group, $p=0.5)$. The reoperation rate was $4.6 \%$ (95\% CI $4.0 \%-5.2 \%)$. The reoperation rate was lower in the sleeve gastrectomy group $(3.1 \% \mathrm{v} .4 .8 \%)$, but the different was not significant $(p=0.1)$. Finally, the leak rate in the study population was $0.84 \%$ (95\% CI $0.61 \%-1.13 \%)$ and was similar in the 2 groups $(0.83 \%$ in the bypass group v. $0.96 \%$ in the sleeve gastrectomy group, $p=0.8$ ).

Table 1: Characteristics of the study population

\begin{tabular}{|c|c|c|c|c|}
\hline Characteristic & $\begin{array}{l}\text { Overall no. }(\%)^{*} \\
\quad n=5007\end{array}$ & $\begin{array}{c}\text { Roux-en-Y gastric bypass } \\
\text { no. }(\%)^{*} \\
n=4591\end{array}$ & $\begin{array}{c}\text { Sleeve gastrectomy } \\
\text { no. }(\%)^{*} \\
n=416\end{array}$ & $p$ value \\
\hline Age, year, mean \pm SD & $44.6 \pm 10.3$ & $44.4 \pm 10.3$ & $47.0 \pm 10.2$ & $<0.001$ \\
\hline Male sex & $907(18.1)$ & $817(17.8)$ & $90(21.6)$ & 0.05 \\
\hline Diabetes & $1483(29.6)$ & $1335(29.1)$ & $148(35.6)$ & 0.005 \\
\hline Hyperlipidemia & $175(3.5)$ & $152(3.3)$ & $23(5.5)$ & 0.02 \\
\hline Obstructive sleep apnea & $1545(30.9)$ & $1375(30.0)$ & $170(40.9)$ & $<0.001$ \\
\hline Chronic kidney disease & $38(0.76)$ & $30(0.65)$ & $8(1.92)$ & 0.004 \\
\hline Hypertension & $1363(27.2)$ & 1209 (26.3) & $154(37.0)$ & $<0.001$ \\
\hline Coronary artery disease & $74(1.5)$ & $61(1.3)$ & $13(3.1)$ & 0.004 \\
\hline COPD & $27(0.5)$ & $21(0.5)$ & $6(1.4)$ & 0.009 \\
\hline GERD & $328(6.6)$ & $293(6.4)$ & $35(8.4)$ & 0.1 \\
\hline Osteoarthritis & $151(3.0)$ & $139(3.0)$ & $12(2.9)$ & 0.90 \\
\hline
\end{tabular}

Table 2: Short-term complications after Roux-en-Y gastric bypass and sleeve gastrectomy*

\begin{tabular}{|c|c|c|c|c|c|c|c|c|c|c|}
\hline \multirow[b]{2}{*}{ Complication } & \multicolumn{3}{|c|}{ Overall } & \multicolumn{3}{|c|}{ Roux-en-Y gastric bypass } & \multicolumn{3}{|c|}{ Sleeve gastrectomy } & \multirow[b]{2}{*}{$p$ value } \\
\hline & $N$ & Rate, \% & $95 \% \mathrm{Cl} \dagger$ & $N$ & Rate, \% & $95 \% \mathrm{Cl} \dagger$ & $N$ & Rate, \% & $95 \% \mathrm{Cl} \dagger$ & \\
\hline Overall & 585 & 11.7 & $10.8-12.6$ & 544 & 11.9 & $10.9-12.8$ & 41 & 9.9 & $7.2-13.1$ & 0.2 \\
\hline Death & 8 & 0.16 & $0.07-0.31$ & 7 & 0.15 & $0.06-0.31$ & 1 & 0.24 & $0.01-1.33$ & 0.5 \\
\hline Reoperation & 231 & 4.6 & $4.0-5.2$ & 218 & 4.8 & $4.2-5.4$ & 13 & 3.1 & $1.7-5.3$ & 0.1 \\
\hline Leak & 42 & 0.84 & $0.61-1.13$ & 38 & 0.83 & $0.59-1.13$ & 4 & 0.96 & $0.26-2.44$ & 0.8 \\
\hline
\end{tabular}




\begin{tabular}{|c|c|}
\hline Variables & OR $(95 \% \mathrm{Cl})$ \\
\hline Female sex (v. male) & $0.74(0.59-0.91)$ \\
\hline Age, yr & $1.01(1.00-1.01)$ \\
\hline $\begin{array}{l}\text { Roux-en-Y gastric bypass (v. sleeve } \\
\text { gastrectomy) }\end{array}$ & $1.15(0.81-1.63)$ \\
\hline Diabetes & $1.21(0.99-1.49)$ \\
\hline Chronic kidney disease & $4.96(2.52-9.75)$ \\
\hline Hyperlipidemia & $0.69(0.39-1.20)$ \\
\hline Obstructive sleep apnea & $1.12(0.90-1.39)$ \\
\hline Hypertension & $1.20(0.96-1.50)$ \\
\hline Coronary artery disease & $0.91(0.44-1.89)$ \\
\hline COPD & $2.43(0.94-6.28)$ \\
\hline GERD & $0.89(0.58-1.36)$ \\
\hline Osteoarthritis & $0.32(0.13-0.80)$ \\
\hline $\begin{array}{l}\text { Note: } \mathrm{Cl}=\text { confidence interval, } \mathrm{COPD}=\mathrm{chr} \\
\text { GERD }=\text { gastresophageal reflux disease, } \mathrm{O}\end{array}$ & $\begin{array}{l}\text { tive pulmonary disease, } \\
\text { tio. }\end{array}$ \\
\hline
\end{tabular}

Table 3 details the results of the fixed effects hierarchical logistic multivariable regression model for overall complications across centres of excellence. The ORs displayed allow for withincentre comparison. Female sex appeared to be protective against complications (OR $0.74,95 \%$ CI $0.59-0.91 ; p=0.006$ ), as was the presence of osteoarthritis (OR $0.32,95 \%$ CI $0.13-0.80 ; p=$ 0.01 , whereas the presence of chronic kidney disease was associated with a nearly fivefold increase in complications (OR 4.96, 95\% CI $2.52-9.75 ; p<0.001)$. Notably, age, type of procedure (i.e., bypass v. sleeve gastrectomy), diabetes mellitus, hyperlipidemia, obstructive sleep apnea, hypertension, coronary artery disease, chronic obstructive pulmonary disease and gastresophageal reflux did not confer an increased risk $(p>0.05)$.

Figures 1 and 2 show variation in outcomes between centres of excellence. Each point on the plots represents the adjusted OR of overall complication or reoperation rate of a particular centre compared with the mean rate. Ratios less than 1 translate to centres with lower complication rates, whereas ratios greater than 1 indicate higher relative complication rates. If the $95 \% \mathrm{CI}$ represented by the error bars does not cross the dashed line, the OR is significantly different from the mean $(p<0.05)$. In Figures 1 and 2, 2 centres of excellence are high performers, with ORs statistically below the mean (centres A and B), where 1 is a poor performer, having overall complications higher than the mean (centre D). The poorest performing centre has an almost fivefold higher OR for overall complications. In Figure 2, centre A is a high performer, with the lowest OR for reoperation compared with the mean, $\mathrm{C}$ is a poor performer, and both $\mathrm{B}$ and $\mathrm{D}$ have reoperation rates similar to the mean. The median OR for overall complications from the hierarchal model was 1.76 . The median OR for reoperation was 1.49. The median OR for both leak rates and death could not be reliably calculated owing to low event rates.
Figure 3 shows the trend over time of the complication rates during the first 3 years of the study. Although overall complication rates remain stable at about $11 \%(p=0.5)$, reoperation, leak and death rates decrease over the study period, with statistical significance reached for both reoperation $(p=0.005)$ and death $(p<0.001)$. In fiscal year 2011 , reoperation rate dropped to $3.79 \%$ and leak rate to $0.66 \%$ with no deaths.

\section{Discussion}

During its infancy period, when this study took place, the Ontario Bariatric Network collaborative had comparable results to other established centres. ${ }^{21-25}$ In addition, using overall complication rate, we have shown a 5 -fold increase in complications between the best performing centre of excellence and the lowest performing centre.

It is worth noting that our reported overall complication rate is high relative to other observational cohort studies, but the definition is not uniform and various limitations using administrative data exist. However, the more important measures, including rates of death, anastomotic leakage and reoperation, were similar. For example, the death rate reported by Burns and colleagues in a national study on bariatric surgery in the United Kingdom was reported as $0.3 \%$, nearly double the mortality we found of $0.16 \% .^{22}$ The UK rate was likely higher because deaths were included to 1 year of follow-up. In a Swedish cohort study of gastric bypass surgery, Stenberg and colleagues reported a leak rate of $1.6 \%$, which is higher than the leak rate after bypass seen in our study $(0.83 \%)$, likely because of their inclusion of deep space abscess. ${ }^{25}$ Hutter and colleagues reported data from the Bariatric Surgery Center Network, citing reoperation rates of 3.0\% after sleeve gastrectomy and 5.0\% after Roux-en-Y gastric bypass, which are similar to our results. ${ }^{23}$

Major morbidity, as shown in the trend over time of the different complications, appeared to decrease during our study period, suggesting that the collaborative learning curve had yet to reach equilibrium in Ontario (Figure 3). It has been suggested that the learning curve for proficiency in bariatric surgery may be more difficult that other laparoscopic procedures and that technical measures of proficiency, such as operative time and postoperative complications, stabilizes at 100 cases for Roux-en-Y gastric bypass in particular. ${ }^{26}$ Surgeons with fellowship training have been shown to reduce not only postoperative complications but also mortality. ${ }^{27}$

Numerous studies have also shown variability in riskadjusted patient outcomes across different hospitals and across different procedures, including bariatric surgery. ${ }^{21,28-31}$

Programs such as the National Surgical Quality Improvement Program have been shown to reduce complication rates at participating hospitals and have proven both cost-effective and cost-saving. ${ }^{32,33}$

\section{Limitations}

The data used was limited to the province of Ontario. In the unlikely scenario in which patients were admitted and 


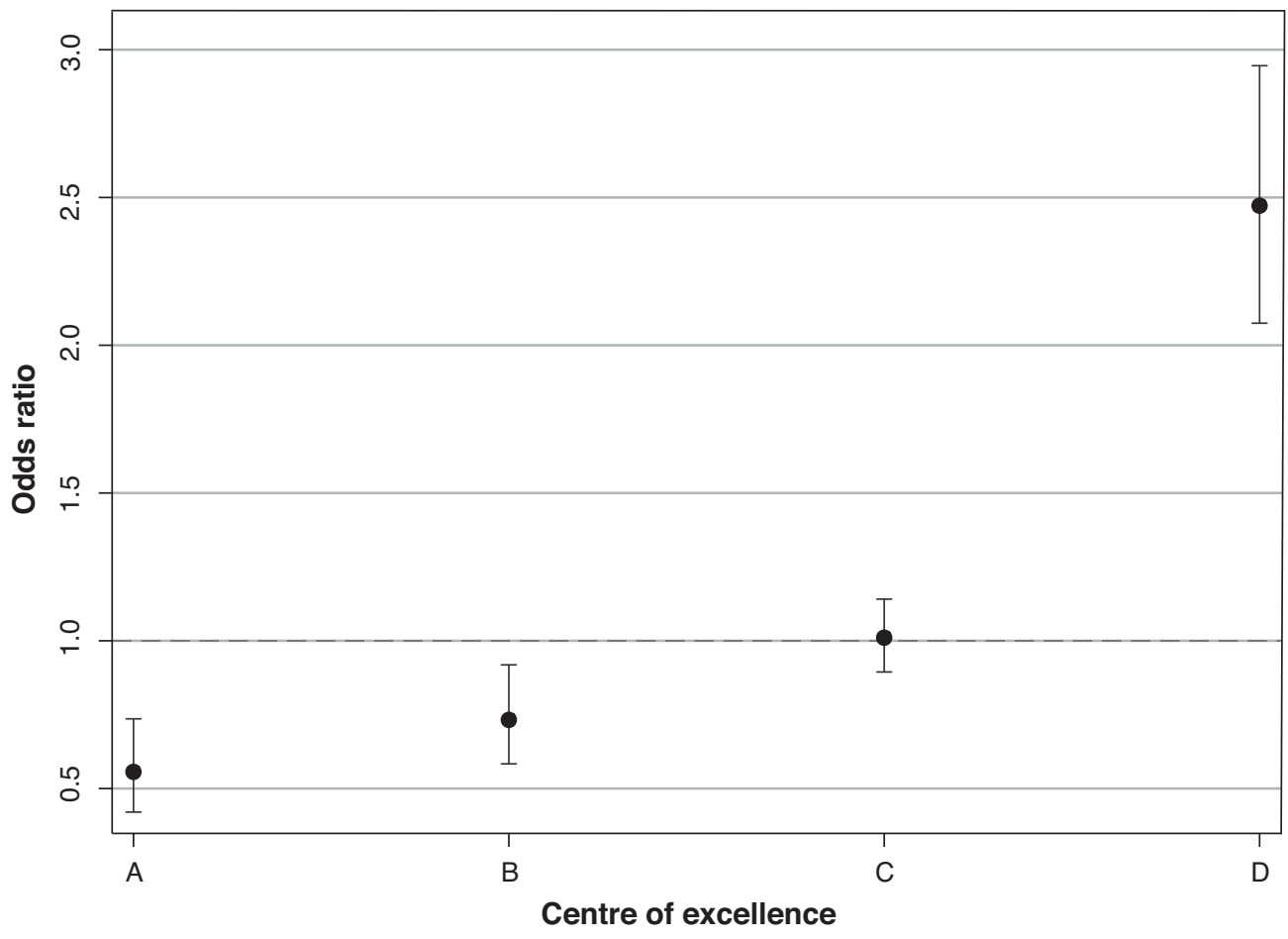

Figure 1: Adjusted odds ratios comparing overall complications of bariatric centres of excellence to the mean overall complication rate. ${ }^{*}$ Results adjusted for sex, age, procedure, diabetes, renal failure, hyperlipidemia, obstructed sleep apnea, coronary artery disease, chronic obstructive pulmonary disease, gastresophageal reflux and osteoarthritis.

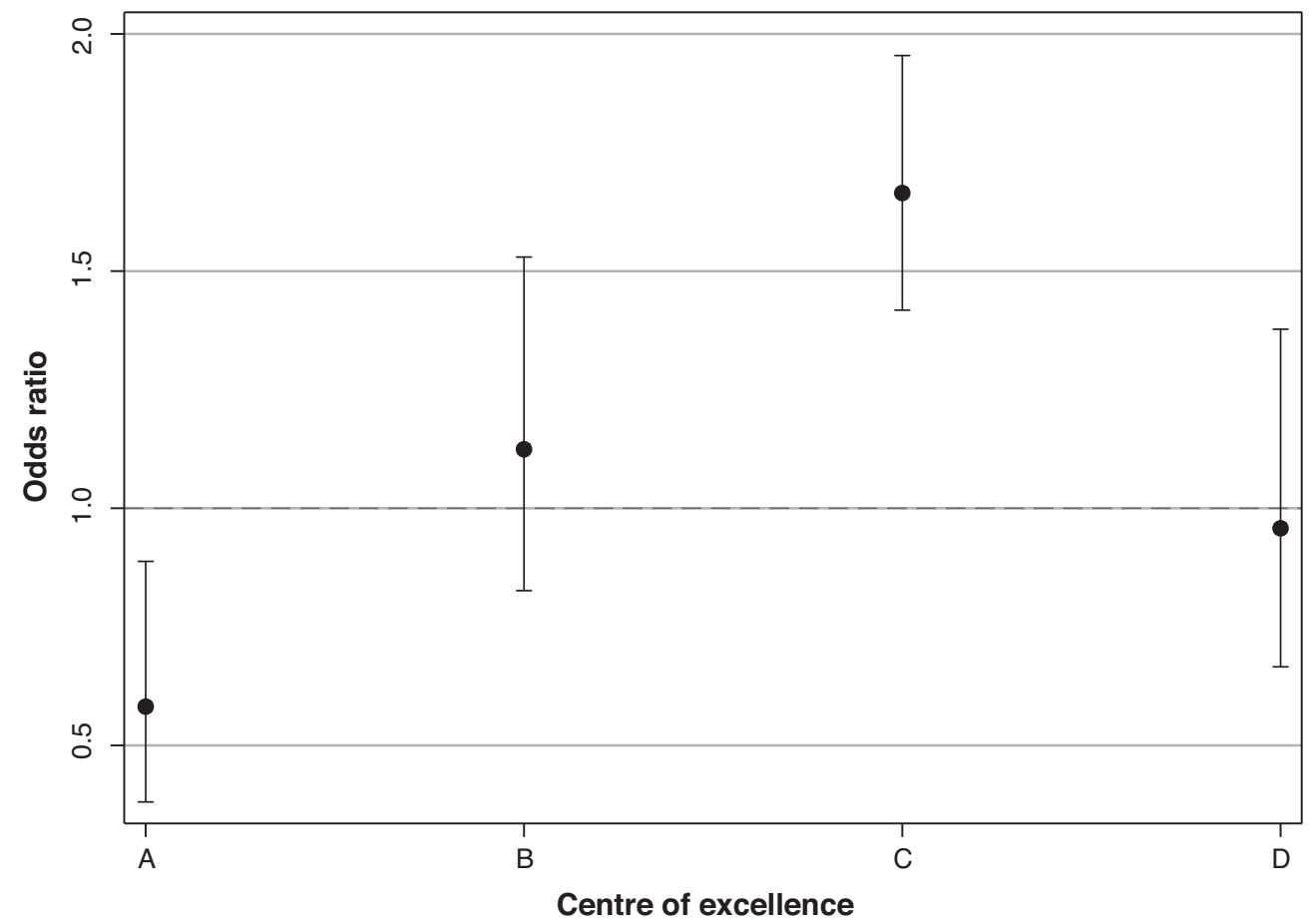

Figure 2: Adjusted odds ratios comparing reoperation rates of bariatric centres of excellence to mean reoperation rate. ${ }^{*}$ Results adjusted for sex, age, procedure, diabetes, renal failure, hyperlipidemia, obstructed sleep apnea, coronary artery disease, chronic obstructive pulmonary disease, gastresophageal reflux, osteoarthritis. 


\section{OPEN}

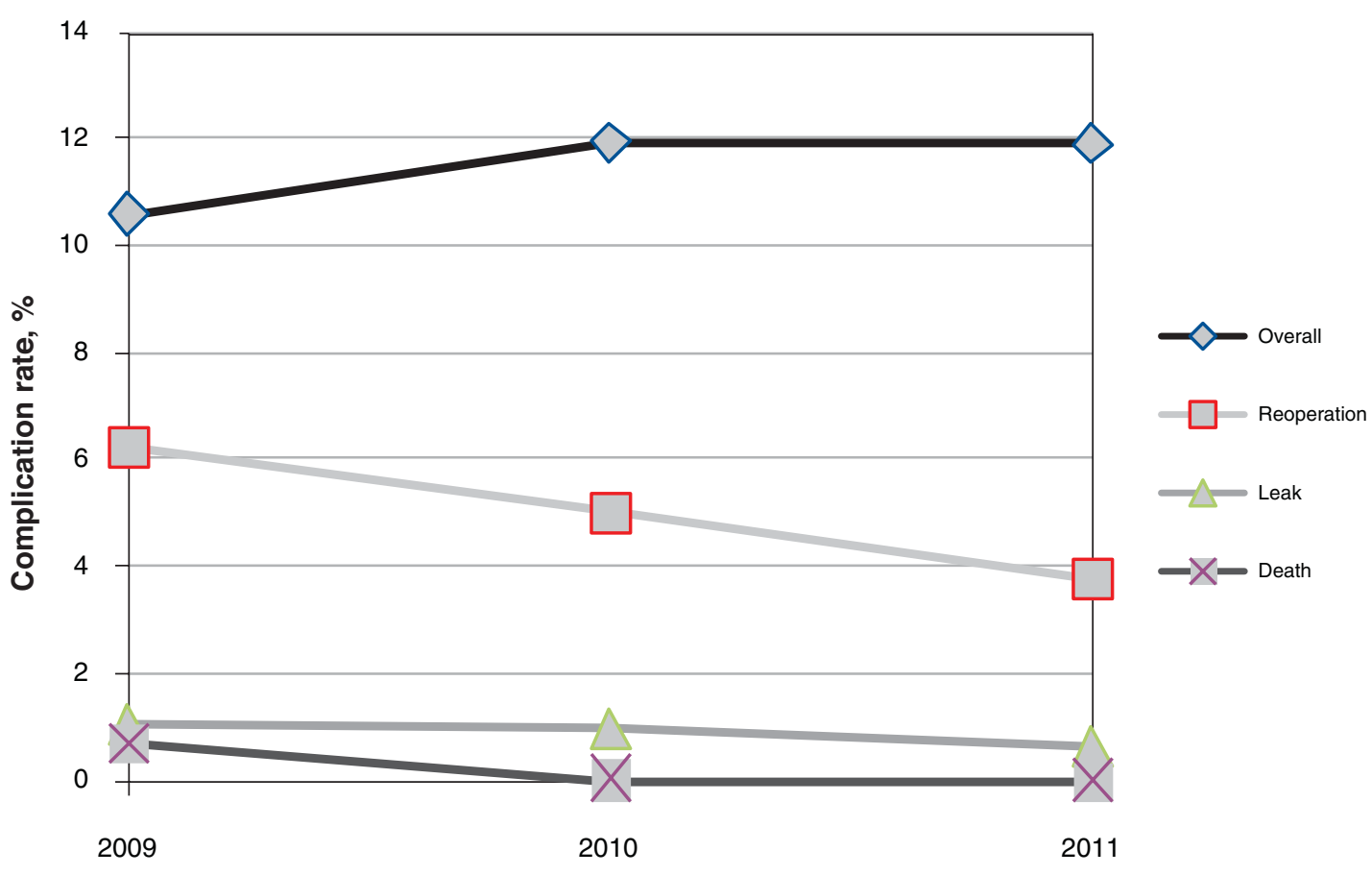

Figure 3: Trends in complication rates over time. Test for trend $p$ values: overall $=0.5$; reoperation $=0.005$; leak $=0.3$; death $<0.001$.

received treatment at hospitals outside the province during their postoperative care, they would not be captured in our data set. In addition, complications listed in the data set, although based on ICD-10 diagnoses, did not uniformly conform to surgical diagnoses. This applies specifically for anastomotic leaks for which we relied on surrogates to inform us of whether or not a leak occurred. Furthermore, trying to standardize complications to make them comparable to other published studies was made difficult for this reason.

Although the Canadian Institute for Health Information database has been shown to be very effective for identifying patients based on procedure codes and most responsible diagnosis, other diagnostic codes have been noted to have much poorer positive predictive values and can thus underestimate certain complications. ${ }^{16-18}$ This may have resulted in an over or underestimation of the leak rate and a likely overestimation of overall complication rate, but we are confident that we are close to the true value because our results are similar to those from other centres. In addition, because the database is an administrative database, it is subject to measurement error, which likely resulted in an underestimation of comorbidity rates. This is particularly true of chronic kidney disease and chronic obstructive pulmonary disease, for which the numbers of patients were quite low, thus making the confidence intervals in the multivariable model quite wide. Although these limitation may influence risk factors for complications, they are unlikely to affect variability in outcomes between centres, because they were all likely to be similarly affected. In addition, a number of sensitivity analyses were performed to see the effect of removing variables with low prevalence from the multivariable model, and the effects were found to be minimal.

We were unable to adjust for all potential confounders in our multivariable model and were limited to the variables provided by the data set. Specifically, we were not able to control for BMI across centres, although data from an internal database (not shown in this study) suggests that BMI is similar between centers of excellence, which gives us confidence that its omission in this study does not affect our results.

\section{Conclusion}

Short-term outcomes of bariatric surgery in Ontario appear to be comparable to those of other major centres and improving over time. Further studies are needed to provide data on the health outcomes in the long term, such as percent excess weight loss, remission or improvement of medical co-morbidity. In addition, further studies exploring reasons behind variations in outcomes between centres of excellence are needed to help bridge the gap and to ensure patients continue to have access to exceptional care.

\section{References}

1. Ng M, Fleming T, Robinson M, et al. Global, regional, and national prevalence of overweight and obesity in children and adults during 1980-2013: a systematic analysis for the Global Burden of Disease Study 2013. Lancet 2014;384:766-81.

2. Twells L, Gregory D, Reddigan J, et al. Current and predicted prevalence of obesity in Canada: a trend analysis. CMAJ Open 2014;2:E18-26.

3. Buchwald H, Avidor Y, Braunwald E, et al. Bariatric surgery: a systematic review and meta-analysis. FAMA 2004;292:1724-37. 
4. Fontaine KR, Redden DT, Wang C, et al. Years of life lost due to obesity. 7AMA 2003;289:187-93.

5. Janssen I. The public health burden of obesity in Canada. Can 7 Diabetes 2013;37:90-6.

6. O'Brian PE, MacDonald L, Anderson M, et al. Long-term outcomes after bariatric surgery: fifteen-year follow-up of adjustable gastric banding and a systematic review of the bariatric surgical literature. Ann Surg 2013;257:87-94

7. Puzziferri N, Roshek TB, Mayo HG, et al. Long-term follow-up after bariatric surgery: a systematic review. $\mathscr{7} A M A$ 2014;312:934-42.

8. Adams T, Davidson LE, Litwin SE, et al. Health benefits of gastric bypass surgery after 6 years. $7 A M A$ 2012;308:1122-31.

9. Buchwald H, Avidor Y, Braunwald E, et al. Bariatric surgery: a systematic review and meta-analysis. 7AMA 2004;292:1724-37.

10. Arterburn DE, Olsen MK, Smith VA, et al. Association between bariatric surgery and long-term survival. FAMA 2015;313:62-70.

11. Andersen JR, Aasprang A, Karlsen T, et al. Health-related quality of life after bariatric surgery: a systematic review of prospective long-term studies. Surg Obes Relat Dis 2015;11:466-73.

12. Ontario Health Technology Maps Project. Toronto: Health Quality Ontario; 2013. Available: www.ontla.on.ca/library/repository/mon/28005/326947.pdf (accessed 2016 June 2)

13. Doumouras AG, Saleh F, Gmora S, et al. Regional variations in the public delivery of bariatric surgery: an evaluation of the Center of Excellence model. Ann Surg 2015;263:306-11.

14. Results-based Plan Briefing Book 2009-2010. Toronto: Ministry of Health and Long-Term Care; 2010. Available: www.health.gov.on.ca/en/common/ministry/publications/plans/rbp_2009_10.pdf (accessed 2015 June 21)

15. Ontario Bariatric Network [website]. Available: www.ontariobariatiricnetwork. $\mathrm{ca} /$ (accessed 2015 June 24).

16. Lee DS, Stitt A, Wang X, et al. Administrative hospitalization database validation of cardiac procedure codes. Med Care 2013;51:e22-6.

17. Austin PC, Daly PA, Tu JV, et al. A multicenter study of the coding accuracy of hospital discharge administrative data for patients admitted to cardiac care units in Ontario. Am Heart $72002 ; 144: 290-6$.

18. Lee DS, Donovan L, Austin PC, et al. Comparison of coding of heart failure and comorbidities in administrative and clinical data for use in outcomes research. Med Care 2005;43:182-8.

19. Gastrointestinal surgery for severe obesity. Consens Statement 1991;9:1-20.

20. Merlo J, Chaix B, Ohlsson A, et al. A brief conceptual tutorial of multilevel analysis in social epidemiology: using measures of clustering in multilevel logistic regression to investigate contextual phenomena. 7 Epidemiol Community Health 2006;60:290-7.

21. Birkmeyer NJO, Dimick JB, Share D, et al. Hospital complication rates with bariatric surgery in Michigan. 7AMA 2010;304:435-42.

22. Burns E, Naseem H, Bottle A, et al. Introduction of laparoscopic bariatric surgery in England: observational population cohort study. BMf 2010;341:c4296.

23. Hutter MM, Schirmer BD, Jones DB, et al. First Report from the American College of Surgeons - Bariatric Surgery Center Network: laparoscopic sleeve gastrectomy has morbidity and effectiveness positioned between the band and the bypass. Ann Surg 2011;254:410-22.

24. Hutter MM, Randall S, Khuri SF. Laparoscopic versus open gastric bypass for morbid obesity: a multicenter, prospective, risk-adjusted analysis from the National Surgical Quality Improvement Program. Ann Surg 2006;243:657-66.
25. Stenberg E, Szabo E, Agren G, et al. Early complications after laparoscopic gastric bypass surgery: results from the Scandinavian Obesity Surgery Registry. Ann Surg 2014;260:1040-7.

26. Schauer P, Ikramuddin S, Hamad G, et al. The learning curve for laparoscopic Roux-en-Y gastric bypass is 100 cases. Surg Endosc 2003;17:212-5.

27. Sanchez-Santos R, Estevez S, Tome C, et al. Training programs influence in the learning curve of laparoscopic gastric bypass for morbid obesity: a systematic review. Obes Surg 2012;22:34-41.

28. Henneman D, van Bommel AC, Snijders A, et al. Ranking and rankability of hospital postoperative mortality rates in colorectal cancer surgery. Ann Surg 2014;259:844-9.

29. van Dishoeck AM, Koek MB, Steyerberg EW, et al. Use of surgical-site infection rates to rank hospital performance across several types of surgery. Br 7 Surg 2013;100:628-37.

30. Livingston E. Bariatric surgery outcomes at designated Centers of Excellence vs nondesignated programs. Arch Surg 2009;144:319-25.

31. The Surgical Quality Improvement Network: improving surgical care in Ontario. Toronto: Health Quality Ontario. Available: www.hqontario.ca/qualityimprovement/nsqip-ontario (accessed 2015 June 21).

32. Hall BL, Hamilton BH, Richards K, et al. Does surgical quality improve in the American College of Surgeons National Surgical Quality Improvement Program: an evaluation of all participating hospitals. Ann Surg 2009;250: 363-76.

33. Hollenbeak CS, Boltz MM, Wang L, et al. Cost-effectiveness of the National Surgical Quality Improvement Program. Ann Surg 2011;254:619-24.

Affiliations: Division of General Surgery (Saleh, Doumouras, Gmora, Anvari, Hong), St. Joseph's Healthcare; Department of Surgery (Doumouras, Gmora, Anvari, Hong), McMaster University, Hamilton, Ont.

Contributors: Fady Saleh, Aristithes Doumouras and Dennis Hong contributed in the design of the study and data analsis. Fady Saleh is credited with writing the manuscript. All authors contributed to the manuscript review, approved the final version for publication and agreed to act as guarantors of the work.

Funding: This work was supported in part by funds from a Regional Medical Associates Grant (A.G. Doumouras and D. Hong)

Supplemental information: For reviewer comments and the original submission of this manuscript, please see www.cmajopen.ca/content/4/3/ E383/suppl/DC1

To promote transparency, CMAJ Open publishes the names of public institutions in research papers that compare their performance or quality of care with other institutions. The authors of this paper have not linked individual institutions to outcome data. We decided to publish this paper without this information, as we felt that it was more important to communicate the finding that variation exists between institutions in decisions about the withdrawal of life-sustaining therapy than to insist on transparency. — Editor, CMAJ Open 